\title{
Commissioning result of the KSTAR in-vessel cryo-pump
}

\author{
Y-B Chang*, H-J Lee, Y-M Park, Y-J LEE, S-W Kwag, N-H Song, D-S Park, J-J Joo, K-M Moon, \\ N-W Kim, H-L Yang, and Y.-K. Oh \\ National Fusion Research Institute, Daejeon, Korea
}

\begin{abstract}
KSTAR in-vessel cryo-pump has been installed in the vacuum vessel top and bottom side with up-down symmetry for the better plasma density control in the D-shape H-mode. The cryogenic helium lines of the in-vessel cryo-pump are located at the vertical positions from the vacuum vessel torus center $2,000 \mathrm{~mm}$. The inductive electrical potential has been optimized to reduce risk of electrical breakdown during plasma disruption. In-vessel cryo-pump consists of three parts of coaxial circular shape components; cryo-panel, thermal shield and particle shield. The cryo-panel is cooled down to below $4.5 \mathrm{~K}$. The cryo-panel and thermal shields were made by Inconel 625 tube for higher mechanical strength. The thermal shields and their cooling tubes were annealed in air environment to improve the thermal radiation emissivity on the surface. Surface of cryo-panel was electro-polished to minimize the thermal radiation heat load. The in-vessel cryo-pump was pre-assembled on a test bed in 180 degree segment base. The leak test was carried out after the thermal shock between room temperature to $\mathrm{LN}_{2}$ one before installing them into vacuum vessel. Two segments were welded together in the vacuum vessel and final leak test was performed after the thermal shock. Commissioning of the in-vessel cryo-pump was carried out using a temporary liquid helium supply system.
\end{abstract}

Keywords : Korea Superconducting Tokamak Advanced Research, In-vessel Cryo Pump, Cryo-panel, Thermal shields, Warm particle shields, Cryogenic helium system, Distribution system, Temporary liquid helium supply system

\section{INTRODUCTION}

The Korea Superconducting Tokamak Advanced Research (KSTAR) facility construction was successfully completed on middle of 2007 and the first plasma demonstrated successfully during the operation periods in 2008. The development of the in-vessel cryo-pump (ICP) began according to in-vessel component upgrade program to enhance the plasma performances in the middle of 2008 . Main function of the ICP is to provide the plasma density control and to limit the impurities entering the plasma core by providing active pumping at each divertor strike point.

The basic design for the KSTAR ICP was based on the cryo-condensation pump of the General Atomics DIII-D. The engineering design was completed through prototype fabrication of 22.5 degree sector in early 2009. And The ICP manufacturing process and assembly sequence was confirmed by prototype. It has been successfully fabricated and installed behind outboard divertor on February 2010. And the commissioning was carried out using temporary liquid helium supply system in 2011. For the active pumping of ICP, connection of helium supply system and fabrication of helium distribution system have to be progressed.

This paper will describe the construction and its commissioning result during $4^{\text {th }}$ KSTAR campaign including the cryogenic system for the KSTAR ICPs.

\footnotetext{
* Corresponding author: ybchang@nfri.re.kr
}

\section{IN-VESSEL CRYO-PUMP SYSTEM}

\subsection{Cryo-pump}

The ICPs are toroidally symmetric and are designed electrically to minimize electric potentials between the ICPs and the vacuum vessel wall while plasma disruptions. The designed pumping speed is 25,000 liter/sec each pump for the impurities gases $\left(\mathrm{H}_{2}, \mathrm{D}_{2}, \mathrm{He}\right)$ with throughput of 20 mbar-liter/sec at deuterium environment (1 mbar).

Figure 1 shows a cross section and 3D modeling with the KSTAR in-vessel component to explain position of the ICPs.

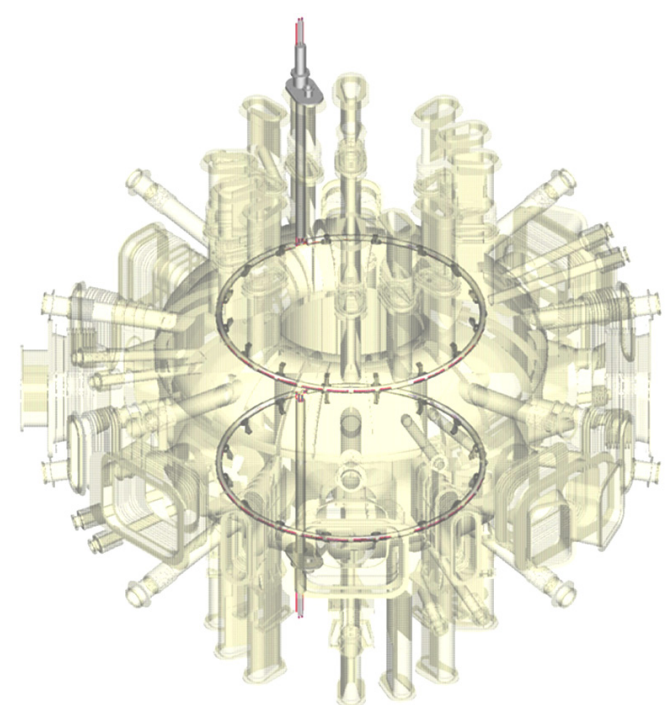

Fig. 1. In-vessel cryo-pump in the KSTAR device. 


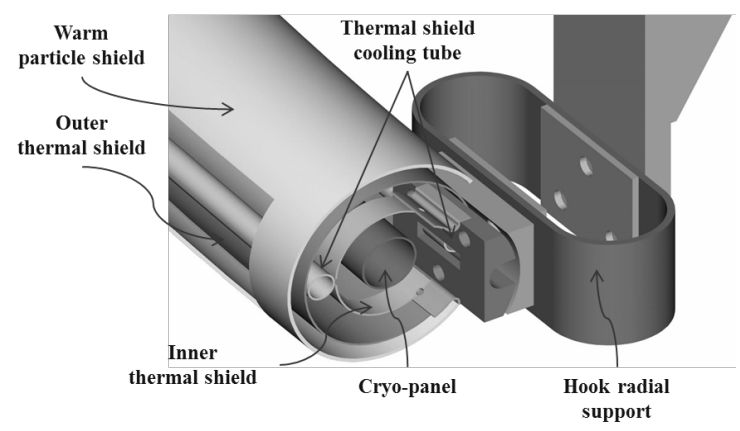

Fig. 2. The configuration of the in-vessel cryo-pump.

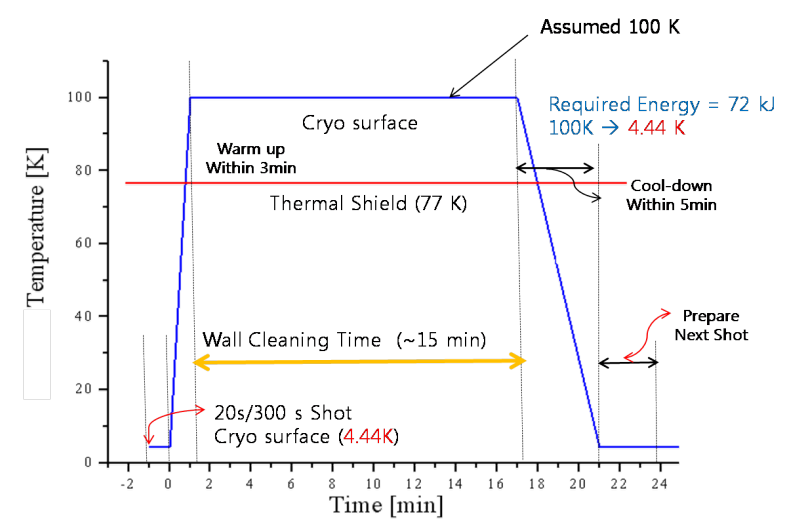

Fig. 3. Regeneration method of the ICPs.

The ICPs are made of Inconel 625 tubes with the length $12 \mathrm{~m}$. As shown in Figure 2, the designed ICP consists of three parts of coaxial circular shape components; a cryo-panel, inner-outer thermal shields and a particle shield. The cryo-panel of $25 \mathrm{~mm}$-diameter is cooled by two-phase liquid helium at $4.44 \mathrm{~K}$ with the inlet pressure $1.24 \mathrm{bar}$.

To increase the flow velocity, heat transfer rate and the stability of the two phase helium flow, a $19 \mathrm{~mm}$-diameter annular tube was inserted in the cryo-panel [3]. To maintain the pumping speed, the cryo-panel has to be regenerated quickly while plasma shot interval. As shown in Figure 3, therefore it should be warmed around $100 \mathrm{~K}$ within 3 minutes and have to be cooled down again to the operating temperature within 5 minutes after maintains about 15 minutes at $100 \mathrm{~K}$.

The cryo-panel is surrounded by the inner-outer thermal shields that are cooled by liquid nitrogen to prevent the thermal radiation heat load on the cryo-panel surface. The thermal shields are surrounded by a warm particle shield to prevent vapor desorption due to striking of energetic particles at the thermal shields and to avoid the thermal radiation from the vacuum vessel wall. The pumping aperture is designed by cutting windows in the thermal shields and warm particle shield. To enhance pumping efficiency of the cryo-panel, the inner-outer thermal shields are designed so that all energetic particles could bounce off the thermal shield surface at least twice before striking the cryo-panel. And the surface of the thermal shields was treated by oxidation annealing in order to high emissivity it caused by absorbing a large fraction of the incoming

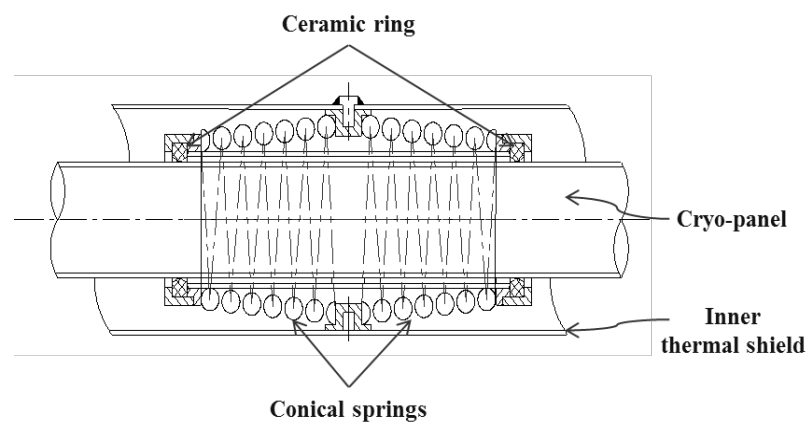

Fig. 4. The helium tube support of the cryo-panel.

thermal radiation. The ICPs were supported by sixteen vertical and hoop radial supports in every 22.5 degree, and the supports were designed to accommodate the external impact such as the thermal stress, electro-magnetic force, and vibration of the vacuum vessel during plasma operation. As shown in Figure 4, the cryo-panel supports consist of conically wound springs with Inconel X-750 and ceramic rings. The supports offer a long heat transfer by the spring and the ceramic rings provide electrical isolation from the thermal shields. The helium tubes of the cryo-panel are supported to the inner thermal shield by a pair of the compressed springs and assembled in the outer thermal shield. The thermal shields are supported to the vacuum vessel wall by the hoop radial support in the radial direction with Inconel 718 and vertical supports with stainless steel $316 \mathrm{LN}$. The hoop radial supports were designed to allow for the differential thermal contraction and expansion between the ICPs at thermal shields and vacuum vessel during operation. The warm particle shield is supported on the outer thermal shield by three-ceramic buttons.

\subsection{Cryogenic system for the cryo-pump}

The cryogenic system that includes the helium system, distribution system, and recovery system will be configured in order to operate the ICPs. The cryogenic system is a closed cycle so that the boiling gas is continuously recovered and re-liquefied. The liquid nitrogen system with storage tank is open cycle so that the exhaust gas being vented to atmosphere. $1 \mathrm{~kW}$ helium refrigeration system [LINDE GROUP] will be constructed using a refrigerator that had been used to supply supercritical helium for the KSTAR SC model coil test. It consists of a compressor system, oil removal system, liquefier with two turbines, gas management system, and utility system. The compressor system supplies 13 bar helium gas with $131.1 \mathrm{~g} / \mathrm{s}$ of mass flow rate to the liquefier system. The high and low pressure of the helium process circuits are maintained at constant pressure by gas management system consisted with the makeup, dump, by-pass valves, and pure helium storage tanks. The helium system was designed to produce liquid helium of $250 \mathrm{liter} / \mathrm{hr}$ in the pure helium operation mode and 150 liter/hr in the impure helium recovery operation mode. Table 1 shows refrigeration and liquefaction capacity of the $1 \mathrm{~kW}$ helium refrigeration systems. 
TABLE I

REFRIGERATION AND LIQUEFACTION CAPACITY.

\begin{tabular}{ccccc}
\hline & Unit & \multicolumn{2}{c}{$\begin{array}{c}\text { Refrigeration } \\
\text { 4.5 K }\end{array}$} & $\begin{array}{c}\text { Liquefaction } \\
4.5 \mathrm{~K}\end{array}$ \\
\hline Inlet pressure & Bar & 13 & 13 & 13 \\
Outer pressure & Bar & 1.06 & 1.06 & 1.06 \\
Turbo expander & No's & 2 & 2 & 2 \\
LN2 precooling & - & YES & NO & YES \\
Comp. mass flow & g/s & 131.1 & 131.1 & 131.1 \\
\hline $\begin{array}{c}\text { Refrigeration } \\
\text { capacity }\end{array}$ & $\mathrm{W}$ & 1,000 & 650 & - \\
$\begin{array}{c}\text { SHe, LHe capacity } \\
\text { * SHe : Supercritical helium, LHe : Liquid helium }\end{array}$ & $\mathrm{g} / \mathrm{s}$ & 75 & 75 & 9 \\
\hline
\end{tabular}

The distribution system was designed to stably divide the flow of the liquid helium and nitrogen to the ICPs and it will be installed KSTAR experimental hall later on. It consists of the vacuum insulated cryostat, sub-cooler, heat exchanger, flow control valves. Table 2 shows the specifications for the cryostat. The vacuum cryostat with a volume $12.5 \mathrm{~m}^{3}$ will be super-insulated with liquid nitrogen thermal shields. The sub-cooler includes the internal components such as a heat exchanger, electric heater, and the cold compressor. It will be cool down to $3.5 \mathrm{~K}$ by cold compressor. Figure 5 shows vacuum cryostat.

TABLE II

SPECIFICATION FOR THE CRYOSTAT.

\begin{tabular}{ccccc}
\hline Item & Sub item & Dimensions & Unit & Remark \\
\hline Chamber & Top plate & $2500 \times 35$ & $\mathrm{~mm}$ & DxT \\
& Cylinder & $2300 \times 3030 \times 12$ & $\mathrm{~mm}$ & DxHxT \\
\hline $\begin{array}{c}\text { Thermal } \\
\text { shield }\end{array}$ & Top plate & $2200 \times 12$ & $\mathrm{~mm}$ & DxT \\
\hline Sub-cooler & Cylinder & $2150 \times 2612 \times 6$ & $\mathrm{~mm}$ & DxHxT \\
\hline \multicolumn{2}{c}{ Cold compressor } & $1100 \times 1050$ & $\mathrm{~mm}$ & DxH \\
\hline
\end{tabular}
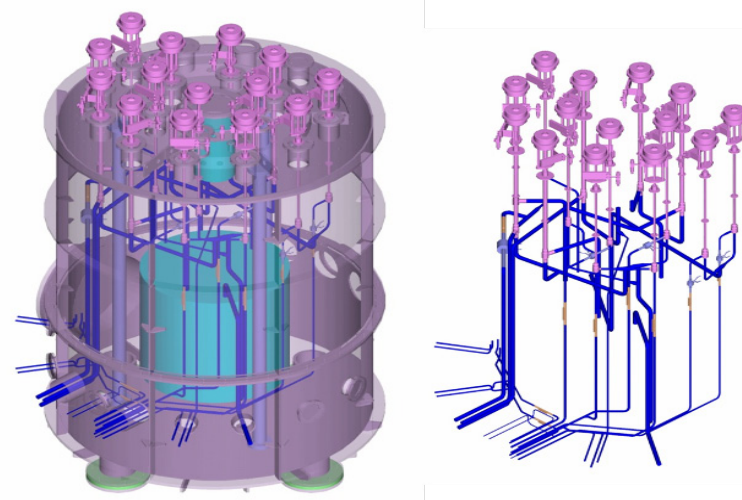

Fig. 5. Dimensional view of the cryostat and inner pipe.
TABLE III

COMPONENTS LIST FOR THE DISTRIBUTION SYSTEM.

\begin{tabular}{|c|c|c|c|c|}
\hline No & Component & Spec & Qnty & Remark \\
\hline \multirow{3}{*}{1} & \multirow{3}{*}{ Control valve } & $\begin{array}{l}\text { Eq.\%,Fail } \\
\text { open }\end{array}$ & 8 & DN10 \\
\hline & & $\begin{array}{l}\text { Eq. } \% \text {,Fail } \\
\text { open }\end{array}$ & 6 & DN25 \\
\hline & & $\begin{array}{l}\text { Quench, Fail } \\
\text { close }\end{array}$ & 1 & DN25 \\
\hline 2 & Safety & 10 bar & 6 & \\
\hline 3 & Warm valve & Manual & 6 & DN10 \\
\hline 4 & Check valve & $\mathrm{LN}_{2}$ One way & 1 & DN50 \\
\hline \multirow{2}{*}{5} & \multirow{2}{*}{$\begin{array}{c}\text { Temperature } \\
\text { sensor }\end{array}$} & Cernox sensor & 9 & \\
\hline & & PT100 & 4 & \\
\hline \multirow{2}{*}{6} & \multirow{2}{*}{$\begin{array}{l}\text { Orifice mass } \\
\text { flow }\end{array}$} & $5 \mathrm{~g} / \mathrm{s}$ & 5 & $\mathrm{LHe}$ \\
\hline & & $10 \mathrm{~g} / \mathrm{s}$ & 2 & LN2 \\
\hline
\end{tabular}

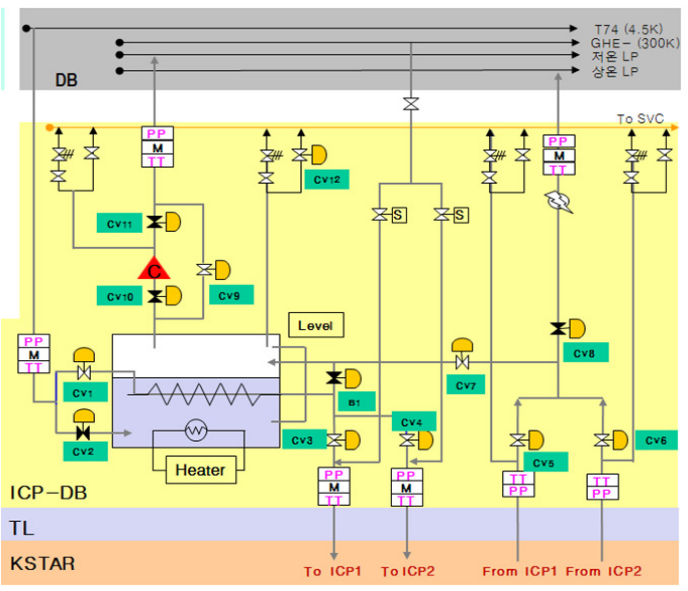

Fig. 6. Flow diagram for the distribution system.

Table 3 shows the components for the distribution system. The flow control valves consist of 13 helium circuit valves, 2 nitrogen circuit valves. The flow diagram of the distribution system is shown in Figure 6. The liquid helium which is made by helium system will flow into the distribution system through 3,000 liter dewar. The sub-cooled helium through heat exchanger will be supplied to each ICPs by the mass flow rate control valves and the supplied liquid helium absorbed thermal energy at ICP will flow into the sub-cooler. It will flow back to the compressor suction line of the helium system by cold compressor. The liquid nitrogen will be fed from 50,000 liter storage by the mass control valves. Through each vacuum jacked transfer line, liquid helium and nitrogen will be supplied.

\section{FABRICATION AND INSTALLATION OF THE ICPS}

The ICPs were fabricated by mechanically rolling with bending radius $2,000 \mathrm{~mm}$ and the cryo-panel and cooling 


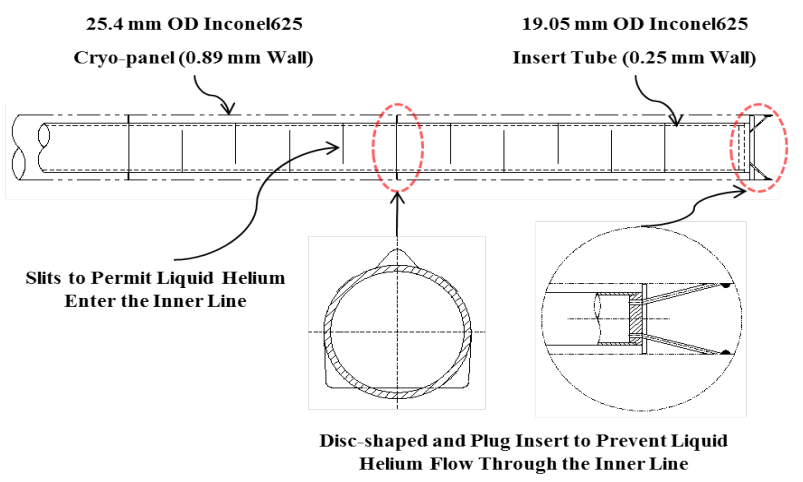

Fig. 7. Inserted annular tube for the cryo-panel.

tubes of the thermal shields were made by seamless tube without welding line by the cold drawing. The surface of cryo-panel was electro-polished at least $0.1 \mu \mathrm{m}$ to enhance the reflectivity and to minimize the radiation heat loads. The annular tube was inserted coaxially inside the cryo-panel. As shown in Figure 7, slits with $0.2 \mathrm{~mm}$ width were machined at the inserted tube in $20 \mathrm{~mm}$ intervals by laser cutting method to permit liquid helium enter into the inner line and it was plugged at $100 \mathrm{~mm}$ intervals by disk shape pieces to prevent liquid helium flow through the inner line. The disk shape was fixed on the inserted tube by 3 point spot welding and end plug was also fixed at each end of the cryo-panel inside by 4 point spot welding using $50 \mathrm{~mm}$-length wire.

The thermal shields were rolled to larger radius than nominal tubes considering thermal contraction due to welding. The cooling tubes were attached to the surface of thermal shields by plug welding into $25 \mathrm{~mm}$ lengths at regular intervals of $50 \mathrm{~mm}$. To reduce the risk of welding defects for all cryogenic components, gas tungsten arc welding (GTAW) method was applied after the certification in compliance with qualification procedure.

The thermal shields were produced as followings; roller bending, laser window cutting for pumping aperture, welding of the cooling tubes with thermal shields, annealing heat treatment, and leakage test. The annealing was performed for $45 \mathrm{~min}$ at $940^{\circ} \mathrm{C}$ to give an oxide layer with a high emissivity and to remove the residual stress by welding. In addition, the outer thermal shield was coated with stripes shape on the outside by plasma spraying using copper powder (METCO 55) to enhance azimuthal thermal conductance. The copper stripes were processed with 25 $\mathrm{mm}$ width at $50 \mathrm{~mm}$ intervals along the longitudinal direction of the thermal shields to reduce the electro-magnetic forces and eddy current on the pump.

The quality inspection of the manufacturing process was implemented for each part. The leakage test was performed by the pressurization test at first and the vacuum leak test after the cold shock using liquid nitrogen in second. The warm particle shield was made by stainless steel $316 \mathrm{~L}$ with process such as roller bending, cut to 22.5 degree sector, laser window cutting for pumping aperture, and fixing of three-ceramic buttons per 120 degree.

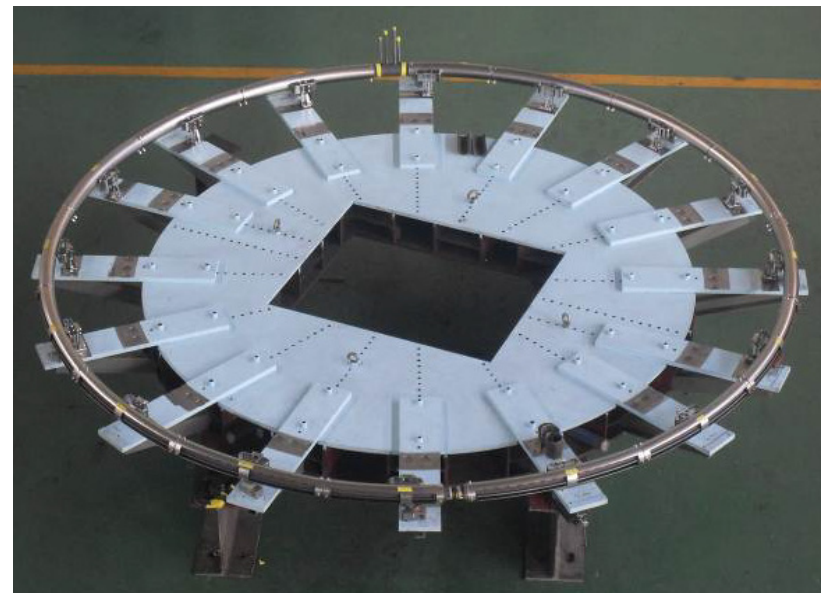

Fig. 8. The pre-assembled ICPs.

The cryo-panel and thermal shields were assembled with 180 degree sector base. The cryo-panel is assembled inside the inner thermal shield, which is installed conically wound springs and thermal shield supports. The inner thermal shield is installed then inside of the outer thermal shield by using a tool that can pull along the moving direction and cooling tube of the inner thermal shied was welded inside of the outer thermal shield by tube fixing jig. The warm particle shields are slide-assembled on the thermal shields and gap of each sector was maintained $3 \mathrm{~mm}$ for mechanical stability during cool down and vacuum vessel wall conditioning.

Finally, the ICPs pre-assembled on the machined table in 360 degree to verify the assembling by all supports and to determine the cut length for cooling tubes of the helium feed line. Figure 8 shows the pre-assembled ICPs.

The ICP leak tests (gas pressurization and vacuum leak test) were performed again before the installation into vacuum vessel.

The ICPs vertical supports were installed to 22.5 degree by a machine which can measure three dimensional displacements. The ICPs were installed by entering sequentially through two middle ports of the vacuum vessel and the connection parts of cryo-panel were welded together.

As shown in Figure 9, the feed line, which are composed of the concentric helium tubes surrounded by the nitrogen thermal shield containing copper stripes with stainless steel $316 \mathrm{~L}$, was also installed through vertically at top and bottom-"O" port of the vacuum vessel. The feed line with the vertical length 3,000 $\mathrm{mm}$ was manufactured by bending at the end point to compensate contraction due to cool down. The ICPs and feed lines were welded including all cooling line for connection parts and assembled with warm particle shield. After the installation completion of the ICPs it was performed finally leakage test after the cold shock using liquid nitrogen, and there was no leakage.

Figure 10 shows the KSTAR ICPs installed into the vacuum vessel. 


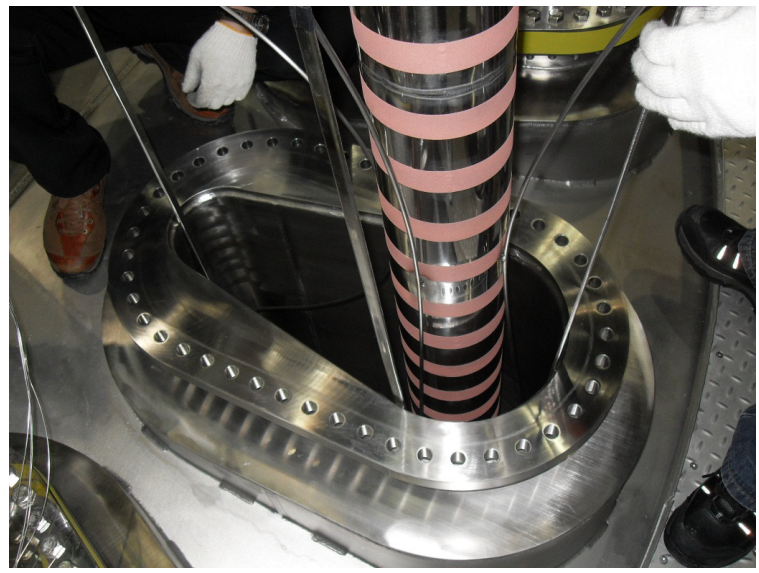

Fig. 9. ICPs feed line installation.

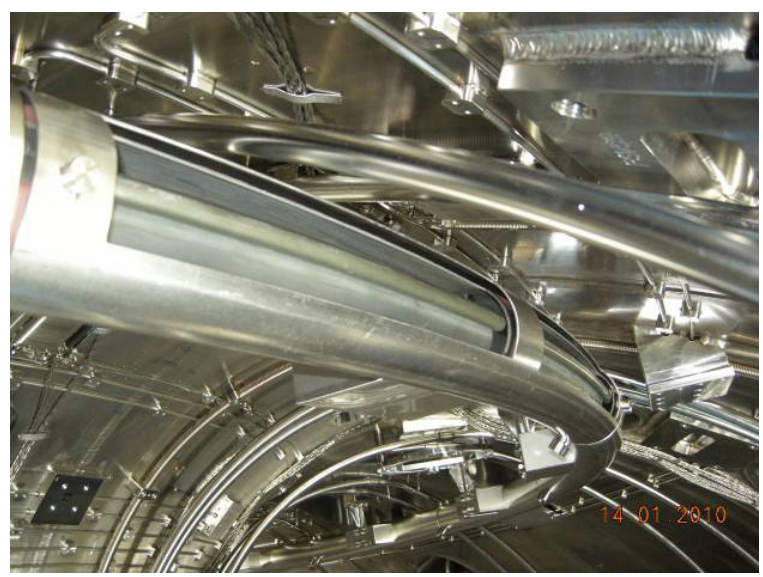

Fig. 10. ICP installed in the vacuum vessel.

\section{COMMISSIONING RESULT}

For commissioning of the lower ICP during the 4th campaign in 2011 , the temporary helium supply system was prepared. The liquid helium was supplied through the "O" port bottom to the lower ICP using a portable helium dewar of 1,000 liter. The helium supply system consists of liquid helium transfer line, vacuum chamber, exhausting line and control system. To control the helium flow rate, temperature sensors and pressure sensors were installed and the helium flow was controlled through remote control in the main control room. The electrical break was installed between the vacuum break chamber and the helium supply system with ISO 250 welded bellows to protect the ceramic break from contraction due to cool down. Inner tubes were also electrically isolated in the vacuum break chamber. The liquid helium flow was controlled by regulated pressure using helium gas bottle. The control valves and regulators were installed on the helium dewar.

In the commissioning results, initial cryogenic cool down was performed successfully without leakage for the cooling line. The elapsed time of cool down was within 15 minutes from $300 \mathrm{~K}$ to $4.5 \mathrm{~K}$ with $4 \sim 5 \mathrm{~g} / \mathrm{s}$ of liquid helium and a

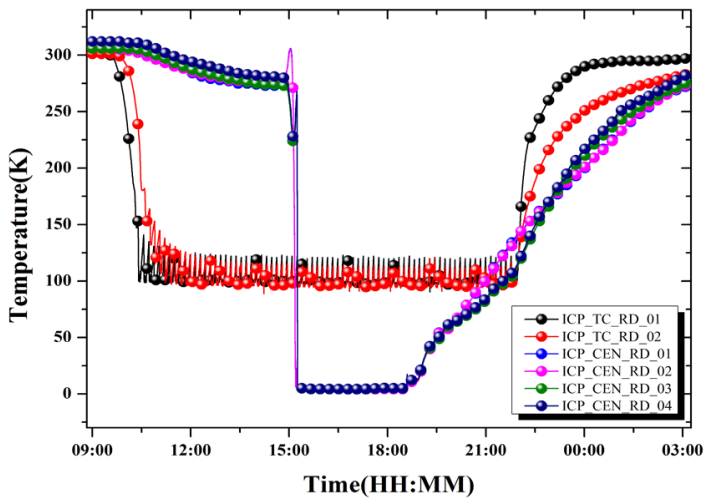

Fig. 11. Cool down curve of the ICP.

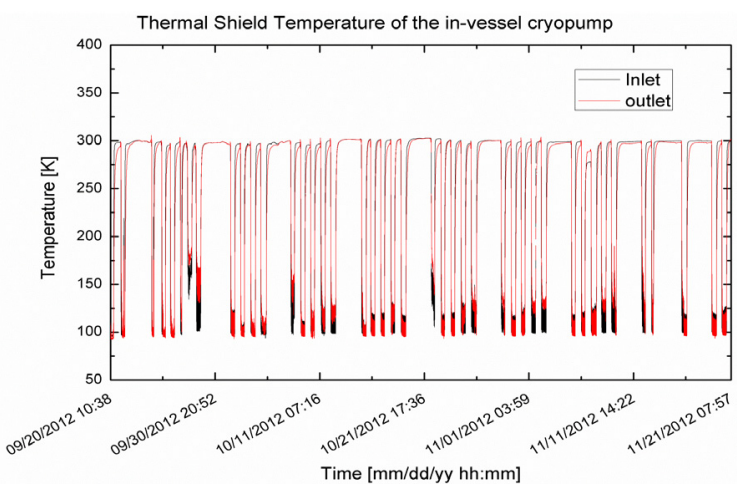

Fig. 12. Cool-down graph of the ICP thermal shield.

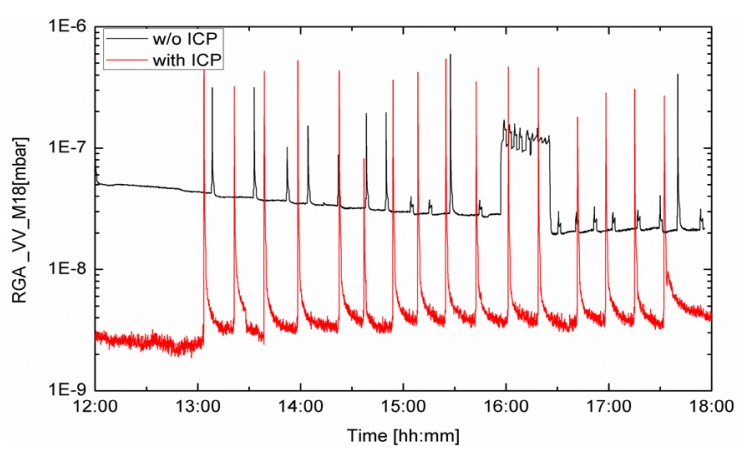

Fig. 13. Vacuum vessel RGA pressure [M18].

cryo-panel kept constant at $4.5 \mathrm{~K}$ during plasma experiment as shown in Figure 11.

During 2012 campaign, the thermal shield of the lower ICP was cooled for 23 days in order to make clean in the vacuum vessel before plasma operation as shown in Figure 12. As a result, the $\mathrm{H}_{2} \mathrm{O}$ residual pressure was reduced below $2.03 \times 10^{-9}$ mbar from $\sim 10 \times 10^{-8}$ mbar thanks to cool-down of thermal shield as shown in Figure 13.

\section{CONCLUSIONS}

The ICPs have been successfully constructed behind outboard divertor in the vacuum vessel by procedure quality inspection for the fabrication and installation on 
February 2010. Which is a six-month with fabrication period of the ICPs, and the installation was completed within two months. The commissioning was carried out using temporary liquid helium supply system for the lower ICP during the 4th campaign in 2011. The lower ICP was cooled successfully without any cold leakage within proper time and maintained cooling for three hours. During the 2012 campaign, the thermal shield of the lower ICP was cooled by $\mathrm{LN}_{2}$ in order to reduce the $\mathrm{H}_{2} \mathrm{O}$ residual pressure in the vacuum vessel. And as a result, it was decreased significantly.

For the continuously active pumping with the KSTAR operation scenario, engineering design that contains the cryogenic helium system and distribution system has been completed on the basis of commissioning result, and the cryogenic system for the KSTAR ICPs will be constructed soon.

\section{ACKNOWLEDGEMENT}

This study is supported by the Ministry of Science, ICT and Future Planning under the KSTAR project.

\section{REFERENCES}

[1] J. P. Smith, C. B. Baxi, et al., "The design and fabrication of a toroidally continuous cryocondensation pump for the DIII-D advanced divertor", J. Fusion Engineering vol 2. 1230 (1991)
[2] J. P. Smith, et al., "Installation and Initial Operation of the DIII-D Advances Divertor Cryocondensation Pump," proc. $15^{\text {th }}$ Symp. On Fusion Engineering, Hyannis, 1993.

[3] G. L. LAUGHON, et al., "Two Phase Liquid Helium Flow Testing to Simulate Operation of Cryocondensation Pump in the DIII-D Tokamak," presented at the $15^{\text {th }}$ International Cryogenic Engineering Conf. Industrial Exhibition, Genoa, Italy, June 7-10, 1994.

[4] J. P. Smith, et al., "Engineering Design of a Radiative Divertor for DIII-D," proc. $16^{\text {th }}$ Symp. On Fusion Engineering, Champaign, IIIinois, 1995, Vol. 1, 858 (1996)

[5] A. S. Bozek, C. B. Baxi, et al., "Engineering Design of Cryocondensation pumps for the DIII-D radiative divertor program", proc. $16^{\text {th }}$ Symp. On Fusion Engineering, Champaign, IIIinois, 1995, Vol. 2, 898 (1996)

[6] E. E. Reis, C. B. Baxi, et al., "Design and analysis of the cryopump for the DIII-D upper divertor", proc. $18^{\text {th }}$ Symp. On Fusion Engineering 519-522 (1999)

[7] P. S. Mauzey, K. L. Holtrop, P. M. Anderson, "Control Improvements for the DIII-D Cryo System", proc. $20^{\text {th }}$ Symp. On Fusion Engineering 1-4 (2005)

[8] H. J. LEE, et al., "Engineering of the KSTAR In-vessel Cryo-pump," 2010 KSTAR Conference, Feb. 2010.

[9] H. J. LEE, et al., "Design and Fabrication of the KSTAR In-vessel Cyro-pump," Volume 86, Issues 9-11, October 2011, Pages 1993-1996

[10] S. W. KWAG, et al., "Commissioning result of the In-vessel cryopump for 4th campaign,” 2010 KSTAR Conference, Feb. 2011. 